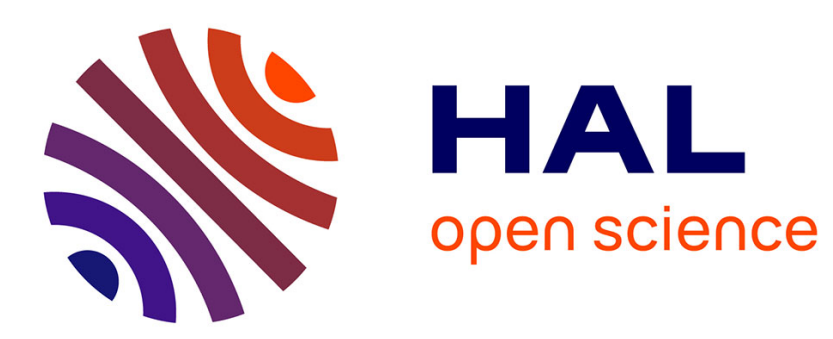

\title{
Atmospheric boundary layers in storms: advanced theory and modelling applications
}

\author{
S. S. Zilitinkevich, I. N. Esau, A. Baklanov
}

\section{To cite this version:}

S. S. Zilitinkevich, I. N. Esau, A. Baklanov. Atmospheric boundary layers in storms: advanced theory and modelling applications. Advances in Geosciences, 2005, 2, pp.47-49. hal-00296830

\section{HAL Id: hal-00296830 \\ https://hal.science/hal-00296830}

Submitted on 29 Mar 2005

HAL is a multi-disciplinary open access archive for the deposit and dissemination of scientific research documents, whether they are published or not. The documents may come from teaching and research institutions in France or abroad, or from public or private research centers.
L'archive ouverte pluridisciplinaire HAL, est destinée au dépôt et à la diffusion de documents scientifiques de niveau recherche, publiés ou non, émanant des établissements d'enseignement et de recherche français ou étrangers, des laboratoires publics ou privés. 
Advances in Geosciences, 2, 47-49, 2005

SRef-ID: $1680-7359 /$ adgeo/2005-2-47

European Geosciences Union

(c) 2005 Author(s). This work is licensed

under a Creative Commons License.

\title{
Atmospheric boundary layers in storms: advanced theory and modelling applications
}

\author{
S. S. Zilitinkevich ${ }^{1,2,3}$, I. N. Esau ${ }^{2}$, and A. Baklanov ${ }^{4}$ \\ ${ }^{1}$ Department of Physical Sciences, University of Helsinki, Finland \\ ${ }^{2}$ Nansen Environmental and Remote Sensing Centre/Bjerknes Centre for Climate Research, Bergen, Norway \\ ${ }^{3}$ Department of Earth Sciences, Uppsala University, Sweden \\ ${ }^{4}$ Danish Meteorological Institute, Copenhagen, Denmark
}

Received: 1 November 2004 - Revised: 21 January 2005 - Accepted: 25 January 2005 - Published: 29 March 2005

\begin{abstract}
Turbulent planetary boundary layers (PBLs) control the exchange processes between the atmosphere and the ocean/land. The key problems of PBL physics are to determine the PBL height, the momentum, energy and matter fluxes at the surface and the mean wind and scalar profiles throughout the layer in a range of regimes from stable and neutral to convective. Until present, the PBLs typical of stormy weather were always considered as neutrally stratified. Recent works have disclosed that such PBLs are in fact very strongly affected by the static stability of the free atmosphere and must be treated as factually stable (we call this type of the PBL "conventionally neutral" in contract to the "truly neutral" PBLs developed against the neutrally stratified free flow).
\end{abstract}

It is common knowledge that basic features of PBLs exhibit a noticeable dependence on the free-flow static stability and baroclinicity. However, the concern of the traditional theory of neural and stable PBLs was almost without exception the barotropic nocturnal PBL, which develops at mid latitudes during a few hours in the night, on the background of a neutral or slightly stable residual layer. The latter separates this type of the PBL from the free atmosphere. It is not surprising that the nature of turbulence in such regimes is basically local and does not depend on the properties of the free atmosphere.

Alternatively, long-lived neutral (in fact only conditionally neutral) or stable PBLs, which have much more time to grow up, are placed immediately below the stably stratified free flow. Under these conditions, the turbulent transports of momentum and scalars even in the surface layer - far away from the PBL outer boundary - depend on the free-flow BruntVäisälä frequency, $N$.

Furthermore, integral measures of the long-lived PBLs (their depths and the resistance law functions) depend on $N$ and also on the baroclinic shear, $S$. In the traditional PBL models both non-local parameters $N$ and $S$ were overlooked.
One of possible mechanisms responsible for non-local features of the long-lived PBLs could be the radiation of internal gravity waves (IGW) from the PBL upper boundary to the free atmosphere and the IGW-induced transport of the squared fluctuations of velocity and potential temperature.

The free-flow stability plays an especially important role in is the conventionally neutral PBLs (those with the zero potential-temperature flux at the surface: $F_{\theta}=0$ at $z=0$, developed against non-zero static stability in the free atmosphere: $N>0$ ).

The above reasoning obviously calls for a comprehensive revision of the traditional theory. In a series of papers (quoted below in References) an advanced theory has been proposed. It includes the following developments.

1 Generalised scaling for the surface layer turbulence accounting for the distant effect of the free-flow stability

In the nocturnal PBL, the proposed generalised scaling reduces to the Monin-Obukhov/Nieuwsadt theory. An additional length scale shown to be critical in the conventionally neutral and long-lived PBLs is $L_{N}=u_{*} / N$, where $u_{*}$ is the friction velocity. Figure 1 (after Zilitinkevich and Esau, 2005) demonstrates its effect on the dimensionless wind shear. Even more important is the effect of $L_{N}$ on the dimensionless temperature gradient (see op. cit.) In the truly neutral PBLs (when $F_{\theta}=0$ at $z=0$ and $N=0$ ), an important role is played by the PBL bulk length scale $u_{*} /|f|$, where $f$ is the Coriolis parameter. 

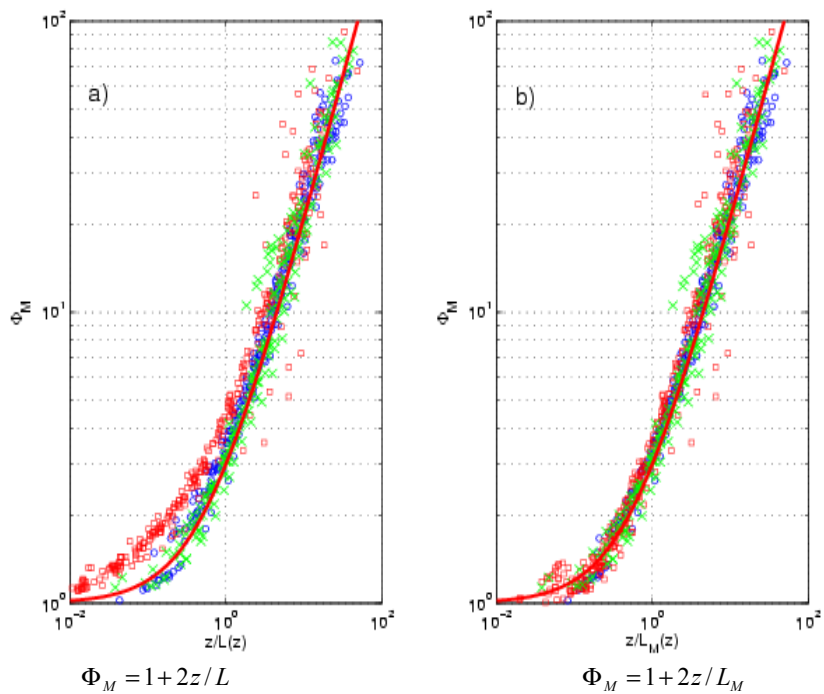

Fig. 1. Velocity shear in stable PBL: $\Phi_{M}=\frac{k z}{\tau^{1 / 2}} \frac{\partial u}{d z}$ versus $\frac{z}{L}$ (a) and $\frac{z}{L_{M}}$ (b). Generalised scale $L_{M}$ defined as $\frac{1}{L_{M}}=\left[\left(\frac{1}{L}\right)^{2}+\left(\frac{C_{N M N}}{\tau^{1 / 2}}\right)^{2}\right]^{1 / 2}$ is used instead of the M-O scale $L=\frac{\tau^{3 / 2}}{-\beta F_{\theta}}$. LES data represent 3 types of the PBL: $x$ nocturnal; o long-lived; and conventionally neutral (CNPBL) typical of strong winds. Theoretical curves are $\frac{\partial u}{\partial z}=\frac{\tau^{1 / 2}}{k z}\left[1+\left(\frac{C_{u} z}{L}\right)\right]$ (a) and $\frac{\partial u}{\partial z}=\frac{\tau^{1 / 2}}{k z}\left[1+\left(\frac{C_{u} z}{L_{M}}\right)\right]($ b).

\section{PBL depth formulation accounting for the free-flow stability, baroclinicity and non-steady processes}

The new formulation covers a wide range of regimes overlooked in earlier works and shows quite narrow limits of applicability of the widely used bulk Richardson number approach. As an example, Fig. 2 (after Zilitinkevich and Esau, 2002,2003 ) shows a very strong effect of the free-flow stability on the depth, $h$, of the conventionally neutral PBLs: more than three times difference between the depths of the truly neutral $(N /|f|=0)$ and typical conventionally neutral $\left(\mu_{N}=N /|f|=10^{2}\right)$ PBLs.

3 Generalised PBL bulk resistance and heat transfer laws accounting for the effects of the free-flow stability and baroclinicity on the A, B and C stability functions

We are dealing with the well known laws $k C_{g}^{-1} \cos \alpha=\ln \left(h / z_{0 u}\right)-A, \quad k C_{g}^{-1} \sin \alpha=-f h u_{*}^{-1} B$ and $k_{T} C_{T R}=\ln \left(h / z_{0 u}\right)-C$, in which $k, k_{T}(\sim 0.4)$ are the von Karman constants; $z_{0 u}$ is the surface roughness; $C_{g}=u_{*} / G$ is the geostrophic drag coefficient ( $G$ is the geostrophic wind speed); $\alpha$ is the cross isobaric angle; $C_{R T}=\theta_{*} / \Delta \theta=-F_{\theta s} /\left(u_{*} \Delta \theta\right)$ is the temperature resistance coefficient; and $\Delta \theta$ is the potential temperature increment across the PBL (namely the difference between the potential

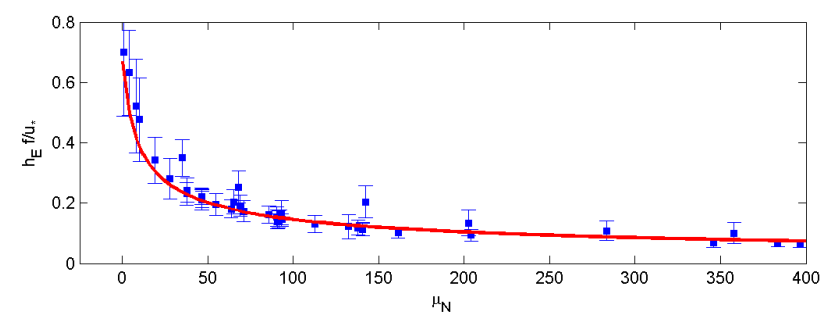

Fig. 2. Dimensionless CNPBL depth $|f| h_{L E S} / u_{*}$ versus imposedstability parameter $\mu_{N}=N /|f|$ after new LES. The theoretical line is $h_{E}=\frac{0.65 u_{*}}{|f|(1+0.2 N /|f|)^{1 / 2}}$.
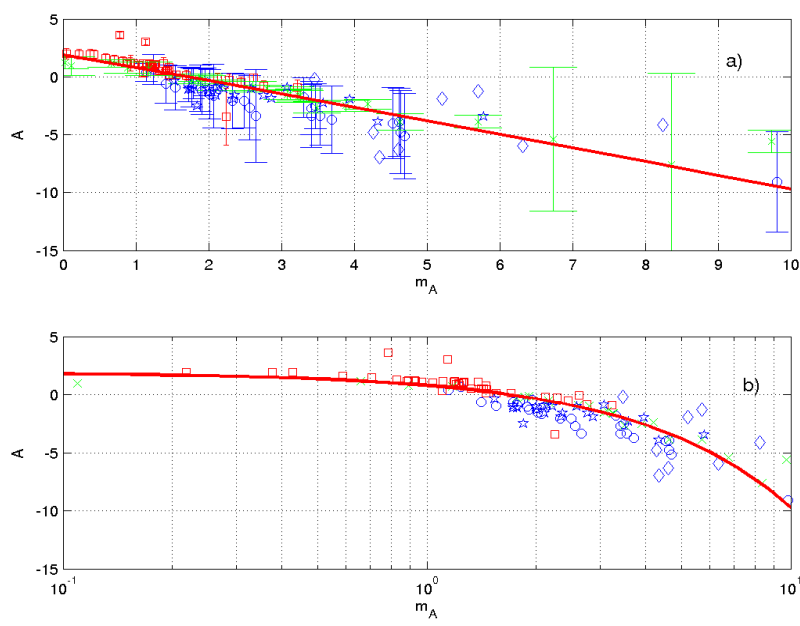

Fig. 3. Geostrophic-drag function $A=\ln \frac{h}{z_{0 u}}-k \frac{u_{g}}{u_{*}} \quad$ vs. $m_{A}=\left[\left(\frac{h}{L_{s}}\right)^{2}+\left(\frac{C_{N A} h}{L_{N s}}\right)^{2}\right]^{1 / 2}$.

temperature at the PBL upper boundary, $\theta_{h-0}$ and the so-called aerodynamic surface temperature $\theta_{0}$. The inclusion of the dependence on $N$ and $S$ resulted in essential collapse of LES data on the $A, B$ and $C$ functions. In other words, the above laws are now rehabilitated as a practical tool for the PBL parameterisation.

According to Fig. 1, the empirical constants are: $\quad C_{N M}=0.06$ and $C_{u}=2 ; \quad$ CNPBL mean profiles are: $\tau / u_{*}^{2}=(1-0.85 z / h)^{3 / 2}$ for momentum flux; $\frac{\partial u}{\partial z}=2.5 \frac{u_{*}}{z}\left(1+0.85 \frac{z}{h}\right)^{3 / 2}+0.3 N$ for the wind shear; and $u(z)=2.5 u_{*} h \int_{z_{0 u}}^{z / h}(1-0.85 \varsigma)^{3 / 2} \frac{d \varsigma}{\varsigma}+0.3 N z$ for the wind speed.

Traditional formula $h_{E}=C_{R} u_{*} /|f|$ for the neutral PBL depth resulted in a wide spread of estimates of the empirical coefficient: $0.1<C_{R}<0.7$.

In Fig. 3 theoretical curve is $A=-1.2 m_{A}+\ln \left(e^{1.9}+m_{A}\right)$, with $C_{N A}=0.09$; new LES are x, o and $\square$ for nocturnal, longlived and CN PBLs; prior LES are $\diamond$ (Brown et al., 1994) and (Kosovic and Curry, 2000). Error bars show \pm 3 standard deviation intervals for each LES run (96\% statistical confidence). Semi-log coordinates better shows CN PBL regime. 

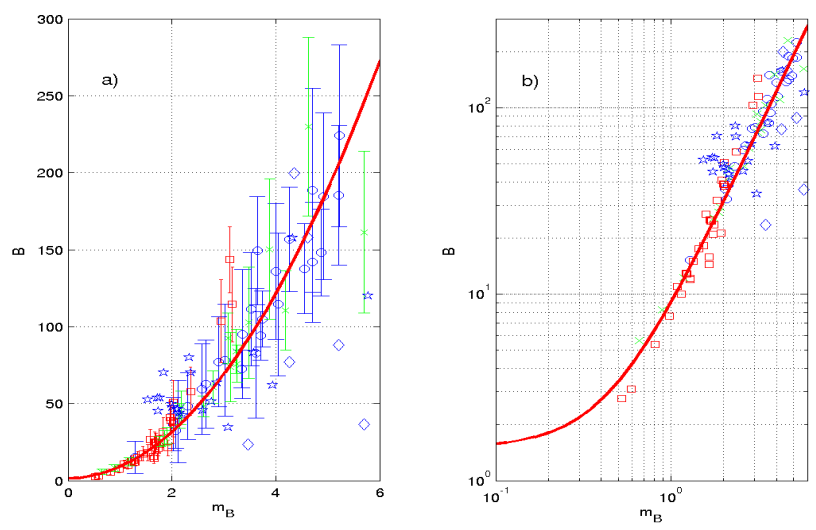

Fig. 4. Cross-isobaric angle function $B=k \frac{v_{g}}{f h}$ vs. $m_{B}=\left[\left(\frac{h}{L_{s}}\right)^{2}+\left(\frac{C_{N B} h}{L_{N s}}\right)^{2}\right]^{1 / 2}$.

In Fig. 4 the theoretical curve is $B=1.5+7.5 m_{N B}^{2}$, with $C_{N B}=0.13$.

\section{Conclusions}

- Atmospheric PBLs in storms are not truly neutral (TN) but conventionally neutral $(\mathrm{CN})$

- Proposed CNPBL model account for strong effects of free flow stability and baroclinicity

- CNPBL depth is typically several times smaller than the TNPBL depth

- Wind profile in the CNPBL is approximately log-linear rather than logarithmic

- The resistance-law coefficients $A$ and $B$ in the CNPBL depend on $\mu_{N}=N /|f|$ (especially important is the effect of $\mu_{N}$ on the cross-isobaric angle coefficient $B$ )

Edited by: L. Ferraris

Reviewed by: anonymous referees

\section{References}

Zilitinkevich, S. and Mironov, D. V.: A multi-limit formulation for the equilibrium depth of a stably stratified boundary layer, Boundary-Layer Meteorol., 81, 325-351, 1996.

Zilitinkevich, S., Johansson, P.-E., Mironov, D. V., and Baklanov, A.: A similarity-theory model for wind profile and resistance law in stably stratified planetary boundary layers, Journal of Wind Engineering and Industrial Aerodynamics, 74-76, 209218, 1998.

Zilitinkevich, S. and Calanca, P.: An extended similarity-theory for the stably stratified atmospheric surface layer, Quart. J. Roy. Meteorol. Soc., 126, 1913-1923, 2000.

Perov, V. and S. Zilitinkevich: Application of an extended similarity theory for the stably stratified atmospheric surface layer to the HIRLAM, HIRLAM Newsletter, No. 35, 137-142, 2000.

Perov, V., Zilitinkevich, S., and Ivarsson, K.-I.: Implementation of new parameterisation of the surface turbulent fluxes for stable stratification in the 3-D HIRLAM, HIRLAM Newsletter, No. 37, 60-66, 2001.

Zilitinkevich, S., Baklanov, A., Rost, J., Smedman, A.-S., Lykosov, V., and Calanca, P.: Diagnostic and prognostic equations for the depth of the stably stratified Ekman boundary layer, Quart. J. Roy. Met. Soc., 128, 25-46, 2002.

Zilitinkevich, S.: Third-order transport due to internal waves and non-local turbulence in the stably stratified surface layer, Quart. J. Roy. Met. Soc., 128, 913-925, 2002.

Soomere, T. and Zilitinkevich, S. S.: Supplement to "Third-order transport due to internal waves and non-local turbulence in the stably stratified surface layer", Quart. J. Roy. Met. Soc., 128, 1029-1031, 2002.

Zilitinkevich, S. S., Perov, V. L., and King, J. C.: Near-surface turbulent fluxes in stable stratification: calculation techniques for use in general circulation models, Quart. J. Roy. Met. Soc., 128, 1571-1587, 2002.

Zilitinkevich, S. S. and Baklanov, A.: Calculation of the height of stable boundary layers in practical applications, Boundary-Layer Meteorol., 105, 389-409, 2002.

Zilitinkevich, S. S. and Esau, I. N.: On integral measures of the neutral, barotropic planetary boundary layers, Boundary-Layer Meteorol., 104, 371-379, 2002.

Zilitinkevich, S. S. and Esau, I. N.: The effect of baroclinicity on the depth of neutral and stable planetary boundary layers, Quart. J. Roy. Met. Soc., 129, 3339-3356, 2003.

Zilitinkevich, S. S. and Esau, I. N.: Bulk resistance and heat transfer laws for geophysical stable boundary layers, Quart. J. Roy. Met. Soc., submitted, 2005. 